\title{
Raman Spectroscopic Analysis of Octocoral Skeletal Mg Dynamics Along a Natural Depth Gradient, Kona Coast, Hawai'i
}

\author{
KYLE CONNER $^{1}$, SHIV SHARMA ${ }^{1}$, RYOHEI \\ UCHIYAMA $^{2}$, KENTARO TANAKA ${ }^{3}$, KOTARO SHIRAI ${ }^{3}$ \\ AND SAMUEL KAHNG ${ }^{1}$ \\ ${ }^{1}$ School of Ocean and Earth Science and Technology, University \\ of Hawai'i at Manoa \\ ${ }^{2}$ Hokkaido University \\ ${ }^{3}$ Atmosphere and Ocean Research Institute, The University of \\ Tokyo \\ Presenting Author: kconner7@hawaii.edu
}

Octocoral skeletal geochemical parameters are of considerable interest in terms of paleoceanographic proxies and their relationships between vital effects and environmental forcing [1]. In particular, the $\mathrm{Mg}$ content of calcitic cold water coral skeletons is thought to be linked to various external and internal factors such as temperature, carbonate ion concentration, seawater $\mathrm{Mg} / \mathrm{Ca}$ ratio, and vital effects associated with annual growth rates [2]. However, relevant studies thus far have been taxonomically and geographically limited to a few species and regions with even fewer analyses considering broader ecosystem scales. We attempt to address this knowledge gap through the analysis of octocoral skeletal $\mathrm{Mg}$ content from samples $(\mathrm{N}=28)$ collected across a natural gradient in depth $(221-823 \mathrm{~m})$ and biogeochemical parameters ( $\left.\mathrm{pH}: 7.3-8.1, \mathrm{~T}: 5-19^{\circ} \mathrm{C}\right)$ off the Kona coast of Hawaii island using the Pisces IV submersible [3]. Raman spectroscopy was used to determine the Mg content of the surface skeleton using prior Raman-based calibration studies of inorganic Mg-calcite [4]. Accompanying oceanographic measurements of temperature, salinity, $\mathrm{pH}$, and TA were used to assess the influence of environmental factors on measured $\mathrm{Mg}$ content patterns. Octocoral $\mathrm{Mg}$ content decreases with increasing depth with differing trends observed between the two octocoral families sampled (Corallidae and Isididae). Additional intrasample Raman measurements were conducted to quantify $\mathrm{Mg}$ variability within selected octocoral samples. A significant relationship between $\mathrm{Mg}$ content and octocoral branch diameter was observed with increased $\mathrm{Mg}$ within the narrower branch tips signifying the presence of faster growing medullar regions of skeleton.

[1] Roberts et al. (2009) Cambridge University Press. [2] Vielzeuf et al. (2018) Front. Earth Sci. 6, 167. [3] Grigg (2002) Mar. Fish. Rev. 64, 13-20. [4] Perrin et al. (2016) Am. Mineral. $101,2525-2538$ 